\title{
ISOLATION AND CHARACTERIZATION OF ACTINOMYCETES FROM SOIL OF AD-DAWADMI, SAUDI ARABIA AND SCREENING THEIR ANTIBACTERIAL ACTIVITIES
}

\author{
GOUSE BASHA SHEIK ${ }^{*}$, MUAZZAM SHERIFF MAQBUL ${ }^{2}$, GOKUL SHANKAR $\mathbf{S}^{3}$, RANJITH MS ${ }^{4}$
}

${ }^{1 *}$ College of Applied Medical Sciences, Ad-Dawadmi, Shaqra University, Saudi Arabia, ${ }^{2}$ Faculty of Microbiology and Immunology, Ibn Sina National College of Medical Sciences, Jeddah, Saudi Arabia, ${ }^{3}$ Faculty of Medicine, AIMST University, Kedah, Malaysia, ${ }^{4}$ Faculty of Medicine, Quest International University, Perak, Ipoh, Malaysia

Email: gbasha@su.edu.sa

Received: 27 Sep 2016 Revised and Accepted: 31 Aug 2017

\begin{abstract}
Objective: To isolate and characterize novel actinomycetes and to evaluate their antibacterial activity against drug-resistant pathogenic bacteria

Methods: In the present study, 19 soil samples were collected from different localities of Ad-Dawadmi, Saudi Arabia. Actinomycetes were isolated from these samples using serial dilution and plating method on Actinomycetes isolation agar supplemented with nalidixic acid and actidione to inhibit bacteria and fungi. Crude extracts of potential actinomycetes were produced by submerged fermentation. The antimicrobial activity of crude extracts of actinomycetes was tested against different bacteria using the agar well diffusion method. Characterization of the isolates was done by morphological, physiological and biochemical methods.

Results: A total of 9 (47\%) isolates of actinomycetes were isolated from 19 different soil samples tested. Among them, 4 (44\%) isolates confirmed as Streptomyces sp. showed potential antimicrobial activity against one or more test organisms. Crude extracts were made from these 4 actinomycetes isolates(DOM1, DOM3, DP3, DP4)and tested for their antibacterial activities against 4 different clinical bacterial strains (Escherichia coli, Pseudomonas aeruginosa, Staphylococcus aureus and Enterococcus). Crude extract from DP3 isolate showed highest antibacterial activity against all the four test organisms $(28 \mathrm{~mm}, 21 \mathrm{~mm}, 20 \mathrm{~mm}$ and $18 \mathrm{~mm}$ ) respectively and DP4 showed lowest antibacterial activity against all the four test organisms (14 mm, $12 \mathrm{~mm}, 0 \mathrm{~mm}, 6 \mathrm{~mm}$ ) respectively. The highest zone of inhibition was shown by DP3 against Staphylococcus aureus (28 mm) and Escherichia coli was resistant for DP4. Most of the Inhibition zones produced by crude extracts showed significant differences when compared with control, tested against test organisms $(\mathrm{P}<0.05)$. Inhibition zones produced by DP3 and DOM1 against Staphylococcus aureus were $28 \mathrm{~mm}$ and 23 $\mathrm{mm}$, respectively which were strong active when compared with control Ciprofloxacin $(18 \mathrm{~mm})$.
\end{abstract}

Conclusion: Further studies for purification of bioactive metabolites and molecular characterization analysis of isolated Streptomyces sp. are in progress which would be helpful in discovering novel compounds of commercial value.

Keywords: Actinomycetes, Drug resistance, Antimicrobial activity, Streptomyces

(C) 2017 The Authors. Published by Innovare Academic Sciences Pvt Ltd. This is an open-access article under the CC BY license (http://creativecommons.org/licenses/by/4.0/] DOI: http://dx.doi.org/10.22159/ijpps.2017v9i10.15402

\section{INTRODUCTION}

Actinomycetes are a group of prokaryotic microorganisms which are gram-positive bacteria with high guanine+cytosine in their DNA [1]. They are considered as biotechnologically important organisms since they are responsible for producing about half of the bioactive secondary metabolites including antibiotics $[2,3]$. They are filamentous bacteria which produce two types of branching mycelium, namely aerial and substrate mycelium. Factors influencing the number and types of actinomycetes present in a particular soil are a geographical location, such as soil type, temperature, organic matter content, moisture content, cultivation and aeration. Actinomycetes act as a major component of the microbial population in most of the soil. About $90 \%$ of the total actinomycetes population consists of Streptomyces species [4]. Soil actinomycetes can produce a wide range of secondary metabolites and about $70 \%$ of the naturally derived antibiotics that are currently in clinical use are produced by them [5]. Almost $80 \%$ of the world's antibiotics are known to come from actinomycetes, mostly from the genera Streptomyces and Micromonospora [6]. A major global healthcare problem has occurred in the 21st century because of increasing resistance of microorganisms against commonly used antibiotics. A renewed search for new antimicrobial agents from Streptomyces has occurred because of this rapid emergence of antimicrobial resistance among pathogenic microorganisms [7]. The most multiple drug-resistant bacteria causing important community-acquired infections include methicillin/oxacillinresistant Staphylococcus aureus (MRSA), vancomycin-resistant Staphylococcus aureus (VRSA), vancomycin-resistant Enterococcus (VRE), extended-spectrum beta-lactamase (ESBL) producing bacteria such as E. coli and Klebsiella spp and penicillin-resistant Streptococcus pneumoniae (PRSP). Therefore, it is important to search for new, efficient and safe antibiotics from actinomycetes sources to overcome the menace of drug-resistant infections. The aim of this present study was to isolate, identify and characterize the actinomycetes isolates from different soil samples from AdDawadmi, Saudi Arabia and to determine their antagonistic activity against selective human pathogenic micro-organisms.

\section{MATERIALS AND METHODS}

\section{Chemicals and media}

Culture media and chemicals used in this study such as Starch Casein agar (SCA), Actinomycetes isolation agar (AIA), Mueller Hilton agar, nutrient broth, starch casein broth, glucose phosphate broth, peptone water, simmons citrate agar, triple sugar iron agar, dimethylsulfoxide, nalidixic acid, actidione, ciprofloxacin were purchased from Himedia Laboratories, Mumbai, India.

\section{Sample collection}

19 Soil samples were collected from different areas of Ad-Dawadmi, Saudi Arabia such as Applied Medical Science College campus, AdDawadmi Park and Ad-Dawadmi old market. Soil samples were collected from 5-25 cm depth in sterile plastic bags and transported aseptically to the Microbiology laboratory, Applied Medical Science College, Ad-Dawadmi. After tacking, soil sample is directly transferred into polyethylene bags to minimize moisture losses during transportation. Clinical strains of bacteria such as Escherichia coli, Pseudomonas aeruginosa, Staphylococcus aureus and Enterococcus were obtained from the Ad-Dawadmi General Hospital, Saudi Arabia. 


\section{Isolation of actinomycetes}

The samples were air dried for one week at room temperature. Isolation and enumeration of Actinomycetes were done by serial dilution and spread plate technique [8]. One gram of soil was suspended in $9 \mathrm{ml}$ of sterile double distilled water and then the dilution was carried out up to $10^{-5}$ dilutions. Aliquots $(0.1 \mathrm{ml})$ of $10^{-2}$, $10^{-3}, 10^{-4}$ and $10^{-5}$ were spread on the actinomycetes isolation agar. To minimize the bacterial and fungal growth, nalidixic acid 100 $\mathrm{mg} / \mathrm{land}$ actidione $20 \mathrm{mg} / \mathrm{l}$ were added respectively. Then the plates were incubated at $30^{\circ} \mathrm{C}$ for $10 \mathrm{~d}$ [9]. The plates were observed intermittently for the actinomycetes growth during incubation. After incubation, actinomycetes colonies which are morphologically distinct were picked from the actinomycetes isolation agar plates and further purified by repeated streak plate method [10]. Once the pure colonies were obtained, each colony was further identified based on its characteristics such as earthy like the smell, colony morphology, the color of hyphae and the presence or absence of aerial and substrate mycelium. Then, selected and identified colonies of actinomycetes were transferred to starch casein agar slant and incubated at $27{ }^{\circ} \mathrm{C}$ for their growth. After incubation, the slants containing pure actinomycetes isolates were stored at $4{ }^{\circ} \mathrm{C}$ for further studies [11].

\section{Screening of actinomycetes and extraction of antibacterial} compound

Clinical strains of bacteria such as Escherichia coli, Pseudomonas aeruginosa, Staphylococcus aureus and Enterococcus were obtained from Ad-Dawadmi General Hospital, Saudi Arabia. The isolates of actinomycete were screened for antibacterial activity against these four clinical isolates using nutrient agar by cross streak method (12). Each nutrient agar plate was streaked with each actinomycete isolate at the center of the plate and incubated at $37^{\circ} \mathrm{C}$ for $6-7 \mathrm{~d}$. Then, 24-hour subcultures of bacteria were streaked perpendicular to the actinomycete isolates and the plates were incubated at $37^{\circ} \mathrm{C}$ for $1 \mathrm{~d}$. After incubation, the zone of inhibition of the test organisms indicates that the actinomycete isolate has antibacterial activity, whereas the full growth of the test organism indicates that the actinomycete isolate has no antibacterial activity. The actinomycete isolates that show potent antibacterial activity (designated as DOM1, DOM3, DP3 and DP4) were selected for extraction of the crude antibacterial compound by submerged culture technique [13]. They were inoculated in $250 \mathrm{ml}$ flasks containing $75 \mathrm{ml}$ of starch casein broth and incubated on a rotary shaker $(200 \mathrm{rpm})$ at $30^{\circ} \mathrm{C}$ for $6 \mathrm{~d}$. A 20liter total volume was filtered through Whatmanno.1 filter paper and then centrifuged at $5000 \mathrm{rpm}$ for $20 \mathrm{~min}$ and the clear supernatant broths obtained was stored at $4{ }^{\circ} \mathrm{C}$ in screw-capped bottles for further study. The supernatant broths were tested for their antimicrobial activity against the selected pathogens by agar well diffusion method [14].

\section{Characterization and Identification of actinomycetes}

Characterization of potent actinomycete isolates was carried out by morphological and biochemical and physiological studies as described in the International Streptomyces Project (ISP) [15]

\section{Morphological Identification}

Gram staining and lactophenol blue staining were done to study the morphology of the actinomycetes cells and spore chain morphology was studied coverslip culture technique with a light microscope (Accuscope 3002 series) [16].

\section{Physiological and cultural characterization}

Colony morphology of the isolates of actinomycete was studied under a high power magnifying lens by observing color of the colony, nature of the mycelium, spore surface and felling the consistency with a sterile loop.

\section{Biochemical characterization}

Actinomycete isolates were characterized by various biochemical tests such as indole test, methyl red test, vogus-proskauer test, citrate utilization test, triple sugar iron test, nitrate reduction test, starch hydrolysis test, catalase test, mannitol and sucrose utilization tests.

\section{Antagonistic activity by agar well diffusion method}

Agar well diffusion method was used to determine the antimicrobial activity of isolates. The supernatant broth containing compounds of actinomycetes was tested for their antibacterial activity against four different clinical isolates namely, Escherichia coli, Pseudomonas aeruginosa, Staphylococcus aureus and Enterococcus. The bacterial test isolates were inoculated in test tubes containing nutrient broths separately and labelled. Then they are incubated at $37{ }^{\circ} \mathrm{C}$ for overnight for obtaining broth cultures. After overnight incubation, bacterial cultures were swabbed in solidified Muller Hinton agar plates and $6 \mathrm{~mm}$ diameter wells were punched in the plate. Then $100 \mu \mathrm{l}$ of supernatant broths containing actinomycetes compounds were dispensed in separate wells. The plates were incubated at $37^{\circ} \mathrm{C}$ for 24 h. After incubation, the diameter of the zone of inhibition around the wells was measured and recorded. The antibiotic ciprofloxacin is used as a control and dimethylsulfoxide without antibacterial compound is used as a blank. Inhibition zones produced by crude extracts showed significant differences when compared with control ciprofloxacin tested against different test organisms $(\mathrm{P}<0.05)$.

\section{Statistical analysis}

The experiment is repeated three times. The mean and standard deviation were calculated. The significance of the differences between the mean values of inhibition zones produced by crude extracts and the control antibiotic tested against test organisms was determined using students $t$-test (using Primer of statistics) and the results were recorded.

\section{RESULTS AND DISCUSSION}

\section{Isolation of actinomycetes}

After processing of the soil samples collected from different areas of Ad-Dawadmi, Saudi Arabia in Microbiology laboratory, Applied Medical Science College, Ad-Dawadmi, a total of $9(47 \%)$ isolates of actinomycetes were isolated from 19 different soil samples. Out of 9 isolates, 2 (22.2\%) were isolated from Applied Medical Science College campus, 03(33.3\%) from Ad-Dawadmi old market and $4(44.4 \%)$ from Ad-Dawadmi park (table 1). Isolation and enumeration of actinomycetes were done by serial dilution and spread plate technique using actinomycetes isolation agar media. All the 9 isolates grown on actinomycetes isolation agar showed morphology typical of actinomycetes. The colonies were slow growing, aerobic, folded and with aerial and substrate mycelia of different colors.

Table 1: Actinomycetes isolates from soil samples collected from different sites of dawadmi

\begin{tabular}{llll}
\hline Collection sites & No. of soil samples & No. of isolates & Isolate number \\
\hline Applied Medical College campus & 6 & 2 & AMC1, AMC2 \\
Dawadmi old market & 6 & 3 & DOM1,DOM2, DOM3 \\
Dawadmi park & 7 & 4 & DP1, DP2,DP3,DP4 \\
\hline
\end{tabular}

\section{Screening of actinomycetes and extraction of antibacterial compound}

All the 9 Actinomycetes isolates were subjected antagonistic activity by cross streak method against 4 types of bacteria, namely,
Escherichia coli, Pseudomonas aeruginosa, Staphylococcus aureus and Enterococcus. As a result of the cross streak method, all actinomycete isolates showed antimicrobial activity against one or more bacterial strains. $4(44.4 \%)$ out of 9 isolates which exhibited high activity against all the pathogens were designated as DOM1, 
DOM3, DP3 and DP4 respectively. For studying antagonistic activity, potential actinomycetes isolates were obtained in pure form by submerged culture technique and preserved at $4{ }^{\circ} \mathrm{C}$ for further studies. In a similar study conducted in soil samples taken from the Garden of Sathyabama University, Chennai, India 13 out of 22 (59\%) actinomycete isolates showed potential antimicrobial activity against one or more test bacteria and/or fungus [17]. In a study conducted in soil samples of different sites of Chambal territory and other parts of Madhya Pradesh, India only 5 out of 85 actinomycete isolates showed antimicrobial activity [18]. In another study conducted in soil samples from Konark and western terrestrial sea. India only 3 out of 20 actinomycetes isolates significant antimicrobial activity [19]. Several other studies have shown that actinomycetes can produce antagonistic molecules that can inhibit or kill the pathogenic microorganisms [20-22].

\section{Characterization and identification of actinomycetes}

The potent actinomycetes capable of high antibacterial activity were characterized by morphological and biochemical characteristics (table 2 and table 3). The observed structure was compared with Bergey's manual of determinative bacteriology [23]. Indole production was strictly negative, methyl red was positive for all except DOM1, vogus-proskauer was negative for all the isolates, citrate positive was for all except DP3, TSI was negative for all the isolates, nitrate reduction was positive for all the isolates except DOM3, starch hydrolysis was positive for all the isolates and catalase was also positive for all the isolates. Mannitol utilization was positive for DP3 and DP4. Sucrose utilization was positive for all the isolates except DP3. After observation of cultural, morphological, physiological and biochemical characteristics it was confirmed that these isolates belong to the species of the genus, Streptomyces. Previous studies conducted by $[13,17-22]$ showed that Streptomyces $s p$. being producers of useful bioactive metabolite have an antibacterial effect with a broad spectrum of activities. Another study showed that among Streptomyces species produced about 7,600 compounds which have antimicrobial properties which are highest among actinomycetes producing antibiotics in the soil [24].

Table 2: Morphological characteristics of potential isolate

\begin{tabular}{|c|c|c|c|c|}
\hline Organism identified & Nature of mycelium & Color of the colony & Spore surface & Gram stain \\
\hline Streptomyces species (DOM1) & extensively branched, aerial and substrate mycelium & white yellow & wrinkled & + \\
\hline Streptomyces species (DOM3) & branched, aerial and substrate mycelium & white pink & wrinkled & + \\
\hline Streptomyces species (DP3) & granular, aerial and substrate mycelium & yellowish brown & smooth & + \\
\hline Streptomyces species (DP4) & branched, aerial and substrate mycelium & creamy & wrinkled & + \\
\hline
\end{tabular}

$+=$ Positive

Table 3: Biochemical characteristics of potential isolates of actinomycetes

\begin{tabular}{|c|c|c|c|c|}
\hline Biochemical test & DOM1 & DOM3 & DP3 & DP4 \\
\hline Indole & - & - & - & - \\
\hline MR & - & + & + & + \\
\hline VP & - & - & - & - \\
\hline Citrate & + & + & - & + \\
\hline TSI & - & - & - & - \\
\hline Nitrate reduction & + & - & + & + \\
\hline Starch hydrolysis & + & + & + & + \\
\hline Catalase test & + & + & + & + \\
\hline Mannitol utilization & - & - & + & + \\
\hline Sucrose utilization & + & + & - & + \\
\hline
\end{tabular}

+= Positive; -= Negative

\section{Antagonistic activity by agar well diffusion method}

The agar well diffusion method is used for the antimicrobial evaluations. In this work, 4 potential actinomycetes isolates were tested for their antagonistic activities against 4 different bacterial strains (Escherichia coli, Pseudomonas aeruginosa, Staphylococcus aureus and Enterococcus.24 hour broth culture of the bacterial strains were used to test the antagonistic activity of crude extracts of potential actinomycetes isolates and mean diameters of the developing inhibition zones(mm) were calculated (table 4). The crude extracts showed antibacterial activities against 4 different bacterial strains with zones of inhibition ranging between 6-28 $\mathrm{mm}$. A total of $9(47 \%)$ isolates of actinomycetes were isolated from 19 different soil samples tested. Crude extract from DP3 isolate showed highest antibacterial activity against all the four test organisms $(28 \mathrm{~mm}, 21 \mathrm{~mm}, 20 \mathrm{~mm}$ and $18 \mathrm{~mm})$ respectively and DP4 showed lowest antibacterial activity against all the four test organisms (14 mm, $12 \mathrm{~mm}, 0 \mathrm{~mm}, 6 \mathrm{~mm})$ respectively. The highest zone of inhibition was shown by DP3 against Staphylococcus aureus $(28 \mathrm{~mm})$ and Escherichia coli was resistant for DP4. Most of the Inhibition zones produced by crude extracts showed significant differences when compared with control, tested against test organisms $(\mathrm{P}<0.05)$. Inhibition zones produced by DP3 and DOM1 against Staphylococcus areas were $28 \mathrm{~mm}$ and $23 \mathrm{~mm}$, respectively, which were strong active when compared with control Ciprofloxacin $(18 \mathrm{~mm})$. The results also showed that the inhibition zones maximum against gram-positive bacteria (Staphylococcus aureus and Enterococcus) when compared to gram-negative bacteria Escherichia coli, Pseudomonas aeruginosa). The reason for lower sensitivity of gram-negative organisms towards antibiotics is due to the difference in cell wall components between these microorganisms, gram-negative bacteria having an outer polysaccharide membrane carrying the structural lipopolysaccharide components which are absent in gram-positive organisms. Several studies on isolation, characterization and antibacterial activity of actinomycetes have been conducted in Saudi Arabia previously. In a study, actinomycetes isolated from soil samples of Jeddah and Al-Madina Al-Munawarah, Saudi Arabia showed antibacterial activity against Staphylococcus aureus, Escherichia coli, and Salmonella typhimurium [25].

Another study shows that actinomycetes isolated from soil samples of Al-Kharj, Saudi Arabia showed antibacterial activity against Staphylococcus aureus, Bacillus subtilis, Streptococcus epidermidis sand Escherichia coli [26]. Several other studies on isolation and characterization of actinomycetes from soil and evaluation of antibacterial activities of actinomycetes against human pathogens also prove that the actinomycetes are able to produce a generation of new antimicrobial agents [17-22]. The results of the present study also support previous studies that the soil actinomycetes have the potential to produce novel antibiotics and were found to be antagonistic against test organisms. 
Table 4: Antagonistic activity of crude extracts of actinomycetes against human pathogens by agar well diffusion method (mm)

\begin{tabular}{|c|c|c|c|c|c|c|}
\hline \multirow[t]{2}{*}{ Test organisms } & \multicolumn{6}{|c|}{ Zone of inhibition (mm) } \\
\hline & DOM1 & DOM3 & DP3 & DP4 & Control & Blank \\
\hline Staphylococcus aureus & $23 \pm 2^{*}$ & $18 \pm 1.39^{\mathrm{NS}}$ & $28 \pm 1.9^{* * *}$ & $14 \pm 2^{\mathrm{NS}}$ & $18 \pm 2$ & $0 \pm 0$ \\
\hline Enterococcus sp. & $15 \pm 2 *$ & $19 \pm 1^{\mathrm{NS}}$ & $21 \pm 1^{\mathrm{NS}}$ & $12 \pm 2 * *$ & $21 \pm 3$ & $0 \pm 0$ \\
\hline E. coli & $8 \pm 1^{* *}$ & $15 \pm 2^{\mathrm{NS}}$ & $20 \pm 2 * *$ & 0 & $13 \pm 2$ & $0 \pm 0$ \\
\hline Pseudomonas aeruginosa & $16 \pm 1^{\mathrm{NS}}$ & $9 \pm 1^{* * *}$ & $18 \pm 2^{*}$ & $6 \pm 2^{* * *}$ & $15 \pm 1$ & $0 \pm 0$ \\
\hline
\end{tabular}

Values are mean $\pm \mathrm{SD}$ of three replications; ( 0 ) denotes no zone of inhibition, $\mathrm{NS}=$ non-significant, ${ }^{*}=\mathrm{P}<0.05,{ }^{* *}=\mathrm{P}<0.01,{ }^{* * *}=\mathrm{P}<0.001$ when crude extracts compared with control, DOM1, DOM3, DP3, DP4 = crude extracts from different isolates; Blank = 1\% Dimethyl sulfoxide; Control = Ciprofloxacin (30 $\mu$ g/ml)

\section{CONCLUSION}

These findings indicated that the soil samples of the Ad-Dawadmi region have actinomycetes with metabolites that control bacterial pathogens. The crude metabolites obtained from four isolates of Streptomyces in our study showed very good antimicrobial activity against four different clinical pathogens. Bioactive metabolites from these Streptomyces sp. have to be purified and molecular characterization of the isolates has to be done for discovering novel compounds which have commercial value. Further studies on these are underway.

\section{ACKNOWLEDGEMENT}

The authors are thankful to the Ministry of Higher Education (MOHE), Shaqra University and Kingdom of Saudi Arabia for funding this research and providing a platform to achieve desired goals in research. We are also very much thankful to the Dean, College of Applied Medical Science at Ad-Dawadmi, Shaqra University, Kingdom of Saudi Arabia for his support and encouragement.

\section{AUTHORS CONTRIBUTION}

1. Study conception and design including acquisition of data: Gouse Basha Sheik

2. Analysis and interpretation of data: Muazzam Sheriff Maqbul

3. Drafting of manuscript: Gokul Shankar S

4. Critical revision: Ranjith MS

\section{CONFLICT OF INTERESTS}

Declared none

\section{REFERENCES}

1. Adegboye MF, Babalola 00. Taxonomy and ecology of antibiotic-producing actinomycetes. Afr J Agric Res 2012;7:2255-61.

2. Yuan L, Zhang Y, Yu L, Sun C, Wei Y, Liu H, et al. Actinopolymorpha cephalotaxi sp. nov., a novel actinomycete isolated from rhizosphere soil of the plant Cephalotaxus fortune. Int J Syst Evol Microbiol 2010;60:51-4.

3. Berdy J. Bioactive microbial metabolites. J Antibiot 2005;58:1-26.

4. Poopal AC, Laxman RS. Studies on the biological reduction of chromate by Streptomyces griseous. J Haz Mat 2009;169:539-45.

5. Elardo PSM, Scheuermayer M, Kozytska S, Hentschel U. Streptomyces axinellae sp. isolated from the Mediterranean sponge. Axinellapolypoides (Porifera). Int J Syst Evol Microbiol 2009;59:1433-7.

6. Pandey B, Ghimire P, Agrawal VP. International Conference on the Great Himalayas: climate, health, ecology, management and conservation, Kathmandu; 2004.

7. Alanis AJ. Resistance to antibiotics: are we in the post-antibiotic era? Arch Med Res 2005;36:697-705.

8. Elliah P, Ramana T, Bapi Raju KVVS, Sujatha P, Uma Sankar AM. Investigation on marine actinomycetes from the bay of Bengal near Karnataka coast of Andhra Pradesh. Asian J Microbiol Biotechnol Environ Sci 2004;6:53-6.

9. Aghamirian RM, Ghiasian AS. Isolation and characterization of medically important aerobic actinomycetes in the soil of Iran. Open Microbiol J 2009;3:53-7.

10. Reddy NG, Ramakrishna DPN, Rajagopal SV. Morphological, physiological and biochemical studies of marine Streptomyces rochei (MTCC 10109) showing antagonistic activity against human pathogenic microorganisms. Asian J Biol Sci 2011;4:1-14.

11. Ramendra SP, Charu S, Pragati S, Ajay K. Isolation and screening of antimicrobial and extracellular pigment producing actinomycetes from Chambal Territory of Madhya Pradesh region, India. Asian J Pharm Clin Res 2016;9:157-60.

12. Nanjwade BK, Chandrashekhara S, Shamarez AM, Goudanavar SP, Manvi VF. Isolation and morphological characterization of antibiotic-producing actinomycetes. Trop J Pharma Res 2010;9:231-6.

13. Atta HM. An antifungal agent produced by Streptomyces olivaceis cleroticus, AZ-SH 514. World Appl Sci J 2009;6:1495-505.

14. Beena J, Joji R. Evaluation of antibacterial activity of the leaf and flower essential oils of Gliricidia sepium from South India. Int J Appl Pharm 2010;2:20-2.

15. Shirling EB, Gottlieb D. Methods for characterization of Streptomyces species. Int J Syst Bacteriol 1966;16:313-40.

16. Nolan R, Cross T. Isolation and screening of actinomycetes. In: Goodfellow M, Williams ST, Mordarski M. editors. In: Actinomycetes in Biotechnology. Academic Press: Inc, California; 1988. p. 1-32.

17. Sudha SKS, Hemalatha R. Isolation and screening of antibioticproducing actinomycetes from the garden soil of Sathyabama University, Chennai. Asian J Pharm Clin Res 2015;8:110-4.

18. Ramendra SP, Charu S, Pragati S, Ajay K. Isolation and screening of antimicrobial and extracellular pigment producing actinomycetes from Chambal territory of Madhya Pradesh region, India. Asian J Pharm Clin Res 2016;9:157-60.

19. Kalyani ALT, Ramya SKM, Annapurna J. Isolation and characterization of antibiotic-producing actinomycetes from marine soil samples. Int J Curr Pharm Res 2012;4:109-12.

20. Sujatha $P$, Swethalatha P. Isolation and screening of novel Streptomyces from sediments of bay of Bengal near Srikakulam coast. Int J Curr Pharm Res 2016;9:40-4.

21. Midhun KD, Girijasankar G. Isolation, screening and characterization of antibiotic-producing actinomycetes from Kapuluppada plastic waste dumping yard, Visakhapatnam. Int J Pharm Pharm Sci 2016;8:221-9.

22. Sreejetha M, Divya, Veena S, Kokati VBR. The bioactive potential of Streptomycesvariabilis-DV-35 isolated from Thottada marine sediments, Kannur, Kerala. Asian J Pharm Clin Res 2016;9:67-71.

23. Kariminik A, Baniasadi F. Phage antagonistic activity of actinomycetes on some gram-negative and gram-positive bacteria. World Appl Sci J 2010;8:828-32.

24. Das S, Ward LR, Burke C. Screening of marine Streptomyces species. for potential use as probiotics in aquaculture. Aquaculture 2010;305:32-41.

25. Saleh MG, Jamal SMS, Amr AMH, Saleh AK, Dina AT, Mohamed MA. Isolation and identification of antimicrobial actinomycetes strain from Saudi environment. J Food Agric Environ 2014;12:1072-9.

26. Muharram MM, Abdelkader MS, Alqasoumi SI. Antimicrobial activity of soil actinomycetes isolated from Alkharj, KSA. Int Res J Microbiol 2013;4:12-20.

\section{How to cite this article}

- Gouse Basha Sheik, Muazzam Sheriff Maqbul, Gokul Shankar S, Ranjith MS. Isolation and characterization of actinomycetes from soil of ad-dawadmi, Saudi Arabia and screening their antibacterial activities. Int J Pharm Pharm Sci 2017;9(10):276-279. 